\title{
Reflexões e problemas da "transmissão" intergeracional no feminismo brasileiro*
}

\author{
Eliane Gonçalves** \\ Joana Plaza Pinto***
}

\begin{abstract}
Resumo
Este artigo parte de uma observação situada do presente e de algumas indagações acerca das possibilidades e limites da transmissão de um ideário - princípios, valores, metodologias, saberes, etc. - através do tempo. O feminismo, enquanto um movimento político coletivo, cujas demandas por reconhecimento e legitimação pressupõem estratégias de formação contínuas, enfrenta, de tempos em tempos, impasses que estão relacionados à sua existência no presente e continuidade no futuro. $\mathrm{O}$ artigo pretende problematizar conceitos $e$ questões em torno do "envelhecimento" das gerações que deram sustentação à política feminista a partir da redemocratização, no Brasil, ao final dos anos 1970, constituindo, no País, o legado da chamada "segunda onda". Nossa perspectiva busca interrogar sobre os processos de mudança social, contingentes e necessários a uma política de "transmissão" e formação de novas gerações.
\end{abstract}

Palavras-chave: Transmissão Intergeracional, Movimento Feminista, Mulheres, Brasil.

\footnotetext{
* Recebido para publicação em janeiro de 2011, aceito em março de 2011.

** Professora da Faculdade de Ciências Sociais/UFG e pesquisadora do SERTÃO Núcleo de Estudos e Pesquisas em gênero e sexualidade/UFG. Cofundadora e colaboradora permanente do Grupo Transas do Corpo. elianego@uol.com.br

**** Professora da Faculdade de Letras da UFG. Colaboradora do Grupo Transas do Corpo desde 1993. joplazapinto@gmail.com
}

cadernos pagu (36), janeiro-junho de 2011:25-46. 
"transmissão" intergeracional no feminismo brasileiro

Reflections and Problems of Intergenerational "Transmission" in Brazilian Feminism

\begin{abstract}
This article is based on an observation of the present and on some questions about the possibilities and limits of the transmission of a set of ideas - principles, values, methodologies, knowledge etc. over time. Feminism, as a political and collective movement, which demands recognition and legitimacy, presumes strategies of permanent formation, and is confronted from time to time, with struggles that are related to its existence in the present and to its continuity in the future. The article aims at questioning concepts about the aging of the generations who gave support to feminist politics during the Brazilian re-democratization process in the late 1970s, which constituted itself the heritage of the so called "second wave". Our perspective aims to interrogate processes of social change, understood as contingent and also necessary, to a politics of intergenerational transmission.
\end{abstract}

Key Words: Intergenerational Transmission, Feminist Movement, Women, Brazil. 
Eliane Gonçalves e Joana Plaza Pinto

\section{Apresentação}

Cada mês do século XX contou tanto para a formação das mulheres quanto todos os séculos anteriores deste milênio.

Fúlvia Rosemberg (1993)

Este artigo parte de uma observação situada do presente e de algumas indagações acerca das possibilidades e limites da transmissão de um ideário - princípios, valores, metodologias, saberes, etc. - através do tempo. O feminismo, enquanto um movimento político coletivo, cujas demandas por reconhecimento e legitimação pressupõem estratégias de formação contínuas, enfrenta, de tempos em tempos, impasses que estão relacionados à sua existência no presente e continuidade no futuro.

$\mathrm{O}$ artigo pretende problematizar conceitos e questões em torno do "envelhecimento" das gerações que deram sustentação à política feminista a partir da redemocratização, no Brasil, ao final dos anos 1970, constituindo, no País, o legado da chamada "segunda onda". A perspectiva adotada busca interrogar sobre os processos de mudança social, contingentes e necessários a uma política de "transmissão" e formação de novas gerações como o pontuam Aikau, Erickson e Pierce (2007), e, de certo modo, também Jean Pierre Terrail (2009). Aikau, Erickson e Pierce (2007) argumentam que é a complexidade das diferentes experiências locais que multiplicam os feminismos no espaço e no tempo, que produzem vozes feministas numa articulação entre as experiências, relações sociais, subjetividade e identidade coletiva. No contexto dessa multiplicidade interseccionada por diferentes marcadores identitários, tempos e espaços, a noção de "transmissão intergeracional" oferece, a princípio, mais desafios que soluções, dado o seu uso corrente em temáticas associadas à psicologia, biologia e sucessão familiar, muito atado à noção de idade e de herança. Nós o utilizaremos enquanto não dispusermos de uma ferramenta conceitual mais apropriada, se é que ela existe. Talvez 
"transmissão" intergeracional no feminismo brasileiro

precise mesmo ser inventada. Vale dizer, ainda, que somos, antes de tudo, estudiosas e ativistas feministas, enfrentando o problema da passagem do tempo e do esvaziamento do "ninho" de nossas organizações e grupos, despertas pela urgência de transformar nossa própria inquietação em objeto de investigação. A questão geracional nem sempre foi uma obviedade $e$ por sua complexidade, requer um fôlego teórico que, todavia, não é possível neste artigo de caráter exploratório. ${ }^{1}$

Essa dimensão do feminismo, que podemos assinalar como "geracional", tem sido provocada no interior do movimento pela intervenção de alguns segmentos jovens que reivindicam voz $e$ presença nos espaços constituídos. No entanto, o fato de se insinuar uma nova força política denominada "jovens feministas" não é suficiente para compreender se, e como, o movimento feminista brasileiro está sendo bem sucedido em sua ambição de continuidade, se é que se pode pensar a importância, para qualquer movimento social, de se ter estratégias de "transmissão" de seu ideário, incluindo-se suas formas de ação ou metodologias. Tendo em conta que esta tarefa não se realiza espontaneamente, mas nos processos de socialização,

faz-se necessário, então, um trabalho sistemático de socialização que garanta, de uma geração a outra, a preparação dos "cidadãos requeridos" para configurações sociais específicas. Portanto, essa perspectiva atribuiu um papel de destaque, no interior das relações intergeracionais, para a dimensão educativa ou socializadora (Tomizaki, 2010:322).

Cabe ressaltar que, atualmente, no Brasil, os estudos feministas que incorporam a categoria geração o fazem, sobretudo, em sua articulação com gênero e outros marcadores de

1 Para explorar tentativas de recuperação histórica do feminismo brasileiro, cf. Soares (1994); Sarti (2004); Pinto (2003; 2010); Manini (1995/96); Pedro (2006); dentre outras. 
diferença e, nesse sentido, podemos vislumbrar, correndo sempre o risco da imprecisão, três eixos predominantes - os que se voltam para o tema do envelhecimento $e$ as discussões sobre o curso da vida, eixo no qual se destacam várias produções já consolidadas de Guita Grin Debert, Alda Brito da Mota e Myrian Lins de Barros; estudos mais recentes que focalizam a juventude ou o protagonismo jovem, tais como as dissertações de Júlia Zanetti (2009) e Érica Isabel Melo (2008) e os que analisam a transmissão intergeracional do ponto de vista do legado do feminismo, seja analisando a sucessão das gerações na família ou biografias individuais (Machado e Lins de Barros, 2009; Machado, 2002), seja interrogando sobre o impacto do feminismo nas gerações presentes e o futuro do movimento (Moraes, 2003; Rago, 1996). Contribuições oriundas da reflexão das próprias protagonistas do movimento de "jovens feministas" começam a despontar em matérias jornalísticas, blogs e livros como os de Fernanda Papa e Raquel Souza (2009).

Compreender este cenário requer conhecer algumas características do feminismo enquanto um movimento político coletivo, internacional, não unívoco e multifacetado, e elaborar perguntas capazes de nortear uma análise do contexto brasileiro.

Das muitas e valiosas definições do feminismo presentes na sua volumosa produção, seguimos a Dominique FougeryrollasSchwebel (2002), que afirma que a luta feminista se apóia no reconhecimento de que as mulheres são oprimidas específica $e$ sistematicamente e que essa opressão não está inscrita na natureza, colocando a possibilidade política de sua transformação. Ou, ainda, nas palavras de Mary Dietz:

O Feminismo é um movimento político e social, local e global, historicamente constituído com uma proposta emancipatória e um conteúdo normativo. Ele afirma um sujeito (mulheres), identifica um problema (a sujeição $e$ objetificação das mulheres através de relações marcadas pelo gênero), e expressa vários objetivos (...) em nome de princípios específicos: igualdade, direitos, liberdade, 
"transmissão" intergeracional no feminismo brasileiro

autonomia, dignidade, auto-realização, reconhecimento, respeito, justiça (Dietz, 2003:399).

Nas periodizações mais frequentes, o feminismo costuma ser dividido em três ondas ou "gerações". A primeira onda, que vai do final do século XIX ao fim da Segunda Guerra Mundial, quando o movimento experimenta um refluxo após as conquistas do direito ao voto em diversos países, inclusive o Brasil ${ }^{2}$, entre outras conquistas no campo legal. A segunda onda se inicia no final dos anos 1960, no rol dos movimentos de contracultura, quando, de fato, se produz uma tentativa de teorizar a opressão da mulher (Pinto, 2003; Rupp, 2002; Gonçalves, 2007). A partir dos anos 1980, emergem as teorias críticas à segunda onda e a categoria unificadora "mulher" perde terreno para a categoria gênero, demarcando fronteiras de classe, raça, sexualidade $e$ localidade (Piscitelli, 2002; Simpson, 2005). Esta última fase constituiria uma imprecisa "terceira onda", que oscila desde a emergência das teorias de gênero, para algumas, ao chamado "pós-feminismo", para outras.

Apesar de ser uma periodização artificial, de certo modo linear, ela é recorrentemente reproduzida em publicações feministas. Clare Hemmings (2009) e Joana Maria Pedro (2006), entre outras, criticam o caráter reprodutivista comum nas publicações feministas sobre tais periodizações. ${ }^{3}$ Hemmings (2009) oferece um útil contraponto ao caráter "etnocêntrico" angloamericano presente em narrativas como estas. Para a autora, é como se o feminismo radical dos anos 1970 ignorasse a diversidade no movimento e somente as teóricas feministas pósestruturalistas a tivessem denunciado. Jane Gallop (1997) enfatiza que parte dessa crítica das teóricas feministas pós-estruturalistas

2 No Brasil, o refluxo ocorre um pouco antes, com o início da ditadura de Getúlio Vargas em 1937 (Pinto, 2003 e 2010).

3 Para uma reconstituição das "ondas" no Brasil com ênfase na literatura feminista, ver Constância Lima Duarte (2003). 
aos "fetiches essencialistas" da categoria "mulher" de suas predecessoras obscurece os contextos e, portanto, os momentos históricos, essencializando a categoria "feminista dos anos 1970": "Não somente 'mulher' não é um universal atemporal, mas nem as feministas o são: não podemos ser eternamente atualizadas" (Gallop, 1997:17). Como aponta a autora, as críticas devem levar em conta "os diferentes momentos de linguagem" a que cada época oferece ao feminismo.

Assim, percebemos que a periodização em ondas, como qualquer outra, é problemática e remete a tensões e relações de poder. Aikau, Erickson e Pierce (2007) oferecem uma adoção crítica desta divisão. As autoras colocam perguntas fundamentais: são as famosas ondas suficientes para explicar as diferenças de tempo no feminismo do século XX? Como entender as aproximações e divergências entre grupos que experimentaram diferentes contextos históricos ainda que os mesmos lugares geopolíticos? Elas argumentam que o binarismo entre a segunda $e$ terceira ondas na historiografia feminista obscurece a multiplicidade de distintas gerações feministas em várias disciplinas $e$ instituições em momentos históricos distintos. $\mathrm{O}$ mesmo pensamento feminista tem uma distribuição desigual em diferentes espaços. Explicitamente contra metáforas familiares para descrever o relacionamento de transmissão geracional, as autoras preferem tomar a metáfora das ondas a sério, pois esta metáfora oferece fluidez e movimento para as análises, ampliando o senso de transmissão fixo. Essas ideias ajudam a adicionar nova perspectiva e admitir as heranças múltiplas feministas em disputa.

Como dito anteriormente, já há algum tempo os movimentos feministas vêm incorporando a geração como marcador socialmente relevante, tanto para problematizar o envelhecimento quanto o rejuvenescimento. De um lado, esta problematização se dá no terreno acadêmico, na formulação de análises que levam em conta a marca da geração nas análises sobre fenômenos diversos - transição demográfica, novas formas e modos de vida, sexualidades etc. - e de outro, ela se dá no 
"transmissão" intergeracional no feminismo brasileiro

terreno da prática política ou da militância, na emergência de agentes que reivindicam espaço próprio e voz no interior do movimento feminista. Esta perspectiva é retomada adiante. Antes, porém, é necessário recuperar brevemente algumas contribuições da chamada "segunda onda" para a prática feminista que teve incidência no Brasil.

O feminismo da segunda onda se popularizou pela estratégia dos grupos de reflexão (consciousness raising groups) cuja característica mais marcante é a ausência de uma estrutura hierárquica ou mesmo formal que invista de especial autoridade ou legitimidade qualquer de suas integrantes. Partindo da proposta de formação coletiva caracterizada pela horizontalidade, as feministas, sobretudo dos EUA, inspiraram outros grupos $e$ organizações em várias partes do mundo ocidental, incluindo a América Latina e o Brasil. Dando ampla centralidade às discussões consideradas privadas, mulheres (descritas geralmente como brancas, intelectualizadas, de classe média) inventaram slogans ao mesmo tempo inovadores e desestabilizadores da ordem. Muitas de suas questões remetiam a situações que as outras formas de organização política não enfrentavam. Assumindo que esta metodologia possuía um potencial transformador e não apenas terapêutico como diziam seus críticos (Grant, 1993), essas feministas da segunda onda produziram conceitos e formas coletivas de organização baseadas na noção de sororidade ou irmandade feminina (Hooks, 1995).

Através de seus slogans - "nosso corpo nos pertence", "o pessoal é político" -, enfatizando que a opressão das mulheres é decorrente de sistemas múltiplos de dominação masculina, o ideário feminista foi se disseminando, sobretudo nas camadas médias intelectualizadas, entre as feministas brasileiras, fornecendo sua metodologia (Alves e Pitangui, 1981; Franchetto et alii, 1981; Gonçalves, 1999 e 2007). No bojo das teorizações e do desenvolvimento de uma metodologia de ação, é possível vislumbrar aproximações e distanciamentos entre as "correntes" 
do feminismo ${ }^{4}$ no que se refere às estratégias em termos de alianças políticas para conduzir à mudança social, à localização do "inimigo comum", às palavras de ordem e às formas de organização (Chinchilla, 1982), estabelecendo prioridade para os espaços institucionais formais (no governo, nas universidades) ou nos grupos informais, marcando sua autonomia.

Diferentemente de outros espaços de organização nos movimentos sociais, o movimento feminista privilegiou uma metodologia que considera a distribuição horizontal de saber $e$ poder entre suas integrantes. Taciana Gouveia observa, a respeito da experiência de transmissão geracional no SOS Corpo - Instituto Feminista para a Democracia (uma das mais antigas organizações feministas brasileiras, ainda atuante) -, que essa distribuição horizontal é fundamental para a transmissão:

os princípios da horizontalidade, igualdade e autonomia que orientam a prática feminista fazem com que cada reunião interna, encontros, seminários, atos públicos, ações de articulação política sejam espaços de imensa e intensa transmissão geracional (Gouveia, 2001:277).

Isso é válido não apenas para as organizações estruturadas, como também para os espaços de decisão do movimento (fóruns $e$ encontros). Assim, rompendo com as formas tradicionais de organização verticalizada, o feminismo se constrói com base na participação efetiva de suas militantes. No Brasil, até os anos 1990, o principal espaço para o debate coletivo eram os encontros feministas nacionais (anuais e, depois, bienais) e latinoamericanos (bienais). Posteriormente, tomaram forma as redes e fóruns locais e regionais, fortalecendo a organização política e dando maior efetividade às campanhas e agendas do movimento. $\mathrm{O}$ feminismo se capilariza em diversos formatos e tendências, ampliando consideravelmente a participação de mulheres de classes

4 Estamos nos referindo aqui à clássica divisão entre feministas liberais, radicais, marxistas/socialistas, característica de narrativas sobre a segunda onda. 
"transmissão" intergeracional no feminismo brasileiro

populares que preferem a alcunha "movimento de mulheres" a movimento feminista (Alvarez, 2004; Soares, 1994).

As redes e fóruns que emergem no Brasil, sobretudo a partir dos anos $2000^{5}$, vinculadas explicitamente a um marcador de identidade política - raça, geração, sexualidade e classe - ou pretendendo realizar na prática a articulação desses marcadores, ao mesmo tempo em que parecem confirmar certa desilusão com a fictícia identidade ou irmandade que ligava as mulheres por uma mesma opressão, plasmada no ideário feminista dos anos 1970, não a rejeitam. Isso pode sugerir que um princípio amplo de "igualdade na diferença" tende a dar sustentação às lutas práticas em favor das mulheres. Como novas organizações no movimento, muitas não dispõem de estrutura formal e se abrigam virtual $e$ fisicamente em espaços já consolidados por outras organizações, oferecendo de imediato um vislumbre sobre acesso desigual a recursos. $\mathrm{Ou}$, quem sabe, o uso compartilhado de espaços tanto físicos quanto virtuais (os sítios na Internet) possa refletir uma estratégia em tempos de escassez de recursos para todas as organizações feministas ao redor do mundo (Awid, 2007).

Outra face igualmente importante do feminismo brasileiro se constrói na academia, muitas vezes de forma híbrida, com ativistas que principiaram nos coletivos informais dos anos 1970 e seguiram carreiras profissionais nas universidades, sendo pioneiras na constituição de núcleos de estudos e pesquisas em anos subsequentes, além de destacado papel na docência (Corrêa, 2001). Judith Stacey (2000:1190) considera o feminismo acadêmico "esta criança muito desejada e nutrida do ativismo popular da 'segunda onda'". Seria interessante indagar se, e

5 Além dos fóruns locais e regionais presentes praticamente em todos os estados brasileiros e da Articulação de Mulheres Brasileiras, criada em 1994, algumas redes feministas que articulam raça, geração, classe e orientação sexual foram criadas a partir de 2000: Articulação de mulheres negras brasileiras (2000), Liga brasileira de lésbicas (2000), Marcha mundial de mulheres (2000), Articulação brasileira de jovens feministas (2004), Articulação de negras jovens feministas (2009). 
como, ensino, pesquisa e extensão - o tripé acadêmico clássico se constituem em espaços ou estratégias privilegiadas de transmissão intergeracional no feminismo brasileiro.

\section{Gênero, geração, política feminista}

Cresce, na atualidade, sobretudo nos grandes centros urbanos de países do Norte, uma tendência a considerar o feminismo como um movimento "datado" cujas premissas não seriam mais relevantes, deixando a cargo das novas gerações a redefinição de seus marcos teóricos de referência, situando-o na contemporaneidade como "pós- feminismo" (Macrobbie, 2006). O sufixo "pós" englobaria, no caso, tanto a negação quanto sua superação, dando a entender que o ideário feminista não encontraria mais lugar nas gerações do presente. Afirmação facilmente contestável a partir de contextos particulares nos quais as desigualdades se sobrepõem (Gonçalves, 2007; Knudsen, 2010). Sintetizando e enfatizando esta posição sobre a persistência das desigualdades de gênero e a consequente relevância do feminismo, em entrevista a Patricia Kudsen (2010:162), Judith Butler afirma:

Suponho que, para algumas pessoas muito estabelecidas e economicamente seguras, o feminismo já não é tão forte, já não é mais um atrativo, porque elas podem muito bem ser mulheres que hoje ocupam postos de poder e privilégio, ou de segurança econômica, mas isso, com certeza, não é verdade globalmente. Se a gente olha para diferentes níveis de pobreza, diferentes níveis de escolaridade, vê que o sofrimento das mulheres é incomensurável.

No Brasil, essa discussão emerge com força no senso comum, facilmente localizável em matérias jornalísticas de ampla circulação. É necessário, ainda, enfatizar que a "morte do feminismo" (Hawkessworh, 2006) é decretada por homens e 
"transmissão" intergeracional no feminismo brasileiro

mulheres - e por razões distintas - que, no presente, encontraram os caminhos abertos por aquelas que de forma mais ou menos solitária enfrentaram a constituição de um movimento.

As jovens feministas brasileiras, de acordo com as recentes pesquisas com alguns segmentos (Zanetti, 2009, Melo, 2008), não recusam os princípios ou bandeiras feministas em si - até porque muitas delas ainda nem foram conquistadas, como é o caso do direito ao aborto legal e seguro -, mas recusam certa forma de organização política, pouco sensível à mudança geracional.

A Articulação Brasileira de Jovens Feministas, marcando uma crítica à dominância das mulheres "adultas" no movimento, se define como uma rede

constituída por mulheres jovens independentes, de organizações e movimentos: negras, lésbicas, indígenas, quilombolas, rurais, da periferia, sindicalistas e de populações tradicionais e provenientes de diferentes regiões do Brasil. Tem um caráter democrático, suprapartidário, anti-capitalista, anti-racista, anti-patriarcal, anti-lesbofóbico, não sexista, não adultocêntrica, não confessional, não hierárquico e não governamental. ${ }^{6}$

É interessante que essa clivagem de geração se dê no interior do movimento feminista, justamente por se mostrar historicamente preocupado com as exclusões. Alda Brito da Mota afirma que o feminismo colocou pioneiramente a relação problemática entre gênero e classe e em suas reescritas críticas colocou a necessidade de articulação entre categorias de diferença, mostrando mais uma vez a importância de se pensar em mulheres como uma categoria plural. Para a autora, o feminismo

vem fazendo isto segundo condições presentes na sucessão do tempo social, em trajetórias teóricas que derivam da

6 Disponível em http://jovensfeministasdesp.blogspot.com [acesso em 23/02/2011]. 
dinâmica da sociedade, e que têm revertido em reflexão e ação sobre a própria trajetória do Movimento, que se veio rendendo às evidências do que o mantém coeso e do que tende a segmentá-lo, e pelo menos as discute" (Brito da Mota, 2000:s/p.).

Como salienta Celiberti (2009:153),

as relações entre adultos e jovens sempre pressupõem certo grau de conflito, mas o conflito não é, de modo algum, o lugar indesejável que nos ensinaram; ao contrário, é um espaço de trocas, de renovação do olhar, de reformulações e revisões.

Nem sempre, todavia, essa retroalimentação, essa possibilidade de produzir a crítica e se deixar afetar pela crítica do outro corresponde às práticas correntes. Olhar as relações intergeracionais do ponto de vista das continuidades $e$ descontinuidades de um movimento - suas crises, avanços $e$ superações - permite compreender como as subjetividades em um campo de ação são permanentemente construídas. A preocupação é bem caracterizada pela autora:

O feminismo abriu a possibilidade de que nós, mulheres, construamo-nos como sujeitos políticos, construtoras de nossa própria trajetória e, dessa perspectiva, abriu também o campo para a diversidade e a pluralidade. Contudo, a gestão dessas diversidades, muitas vezes, colocou o movimento como um elemento paralisante, ou ao menos infecundo, no sentido de motivar o debate de ideias, a confrontação intelectual, o enriquecimento teórico $e$ político. Ao discutir com uma jovem, corro o risco de ser acusada de adultocêntrica; se uma jovem discorda de mim, talvez não consiga me separar do todo e coloque todas as "velhas" feministas no mesmo saco. Então, aqueles caminhos, que abrimos e que representaram rupturas epistemológicas significativas, voltam a fechar-se em nossa 
"transmissão" intergeracional no feminismo brasileiro

prática política. A diversidade não é o espaço despolitizado para que cada um seja como quiser neste mundo consumista e mercantilista. Mas também não é a caça às bruxas do politicamente correto. Reconhecer a singularidade de cada uma - jovem, negra, lésbica, trabalhadora rural, operária $e$ todas as infinitas combinações possíveis entre qualquer uma destas categorias nômades - significa, para mim, saber que cada uma vai me desafiar a olhar por um ângulo que eu não vejo e que, ao considerar esse ponto de vista, mudo totalmente a minha perspectiva. Mas é claro que também espero e desejo reciprocidade nesse intercâmbio (Celiberti, 2009:153).

Para algumas jovens feministas o problema que se coloca é de assimetria, de acesso diferenciado a poder, de falta de legitimação de suas falas. Inspirada em Pierre Bourdieu, Zaneti traduz bem a questão da assimetria em termos de poder $e$ capital simbólico, no confronto entre as gerações de feministas, confronto que se expressa pelo sentido de "herdeiras" de um legado, condição que se alteraria apenas em face da ausência das "feministas históricas" (Zaneti, 2009:40), ou seja, sua morte ou afastamento definitivo.

Esta mesma compreensão encontra-se na dissertação de Érica Melo (2008) que, apoiada no texto clássico da sociologia de Karl Mannhein, compreende que a geração está inserida na dinâmica da transmissão do acervo cultural, ou seja:

a herança e a criação cultural está sujeita ao surgimento de novos participantes e desaparecimento de antigos. A geração ainda está ligada ao ritmo de mudança social e é nesse ponto que se encontra a importância da juventude, pois o estilo geracional é engendrado nessa fase. É nesse momento que as pessoas refletem e questionam as informações recebidas, que os problemas se localizam num "presente" e são experimentados enquanto tais (Melo, 2008:73). 
Formulamos esta discussão para os movimentos feministas, mas ela se aplica a qualquer movimento social contemporâneo. Referindo-se ao Partido dos Trabalhadores, Fernanda Estima (2010) afirma que a geração jovem que deseja ser protagonista agora estava na infância ou nem havia nascido nos anos 1980 e suas aspirações certamente diferem dos sonhos e aspirações de seus "pais".

Drica Madeira, ligada ao Partido Comunista do Brasil, no Rio de Janeiro, referindo-se especificamente ao feminismo numa entrevista, denuncia o envelhecimento ou enrijecimento do movimento, tomando por base não apenas o quesito geracional, mas também, ideológico e metodológico:

Em minha opinião, no Brasil existe um vácuo geracional entre as feministas e como conseqüência um vazio temporal nas suas formulações. Vai desde as áreas de concentração de estudo até o que deve ou não ser incorporado teoricamente ou mesmo conceitualmente às nossas concepções. Do ponto de vista da prática política então, é uma distância enorme. Os velhos modelos ainda hegemônicos afastam as novas gerações de mulheres, o movimento embrutecido e burocratizado não deita raízes na vida real das brasileiras, não interessa mais (Madeira, 2010:2).

É difícil caracterizar essa parcela do movimento em termos apenas etários uma vez que a idade máxima oscila em torno dos 25-30 anos e não é um medidor "sensível", já que muitas lideranças permanecem nas articulações mesmo depois de completarem os 30 anos. Ao que parece, a formação de uma vertente jovem no feminismo advém mais de reformulações dentro do próprio feminismo, com a problematização da categoria unificadora "mulher", do que por novas demandas resultantes de novas relações marcadas por gênero e geração. A agenda política feminista, afinal, não mudou tanto nos últimos 20 ou 30 anos salário igual para trabalho igual, maternidade voluntária, acesso à 
"transmissão" intergeracional no feminismo brasileiro

saúde sexual e reprodutiva, incluindo aborto legal, seguro e gratuito, combate à violência contra a mulher, autonomia sexual $e$ controle sobre o próprio corpo, para mencionar apenas alguns itens. Então, o que se coloca, ao que parece, é, de um lado, a relação marcada pelo silenciamento ou invisibilização de alguns sujeitos do feminismo e, dentre estes, as jovens; e, de outro lado, a hegemonia de sujeitos adultos, as "feministas históricas", às vezes apresentadas de forma caricata como "fósseis", "dinossauras", "pré-históricas". 7

A ênfase concedida à emergência de um debate geracional no interior do feminismo brasileiro não pretende reificar a questão da idade, porque processos de "transmissão" ultrapassam o enfoque intergeracional apenas enquanto "sucessão". Gouveia (2001:277) aponta esta contradição ao confrontar a ideia de que "transmissão geracional é um processo [que] geralmente está associado à questão da ocupação de lugares de poder", e propõe que vejamos a transmissão geracional como operando "na formação e na construção do conhecimento, mesmo que de um modo informal ou sem estratégias e objetivos muito claros". Recusando a polaridade simples entre a cultura e a natureza do par idade/geração, Brito da Mota (2000:s/p) alerta:

$\mathrm{Na}$ discussão mais recente sobre categorias relacionais $e$ construções culturais, quando se vai até as idades, tem-se sugerido a equivalência do par de conceitos idade/geração com outros pares já mais trabalhados teoricamente: geração estaria para idade como gênero está para sexo e etnia para raça. Isto é, ter-se-ia uma elaboração de ordem cultural ou simbólica sobre o seu correspondente par biológico. Reluto, diante desse dualismo tão simples. O "biológico" idade, referente ao tempo "natural", não é também de inscrição tão subjetiva nos indivíduos e nos grupos, no seu

7 Rose Marie Muraro prefere se autodefinir como "pré-arcaica". Cf.: Folha de S. Paulo, Cotidiano, 08 mar. 2011. Entrevista a Eleonora de Lucena. 
desconstruir-se/(re) construir-se anual, ao sabor das representações culturais de cada grupo?

Para o feminismo, é necessária essa diferenciação, de que geração não se confunde com idade, pois, se pensarmos em termos de socialização, é fácil chegar à conclusão de que muitas mulheres se tornam feministas ou adquirem uma consciência feminista depois de experimentar várias situações no curso da vida: casamento, maternidade, sexualidade, trabalho formal etc., todas elas referidas necessariamente a uma condição de classe, a um pertencimento étnico e racial, a uma orientação sexual, a uma determinada localidade e assim por diante. Assim, se a transmissão intergeracional é "uma via de mão dupla, onde as diferentes temporalidades interagem continuamente" (Gouveia, 2001:276), pensar a transmissão intergeracional no feminismo brasileiro nos remete necessariamente à questão: num tempo de ativismo historicamente determinado, todas nós fomos ou nos sentimos jovens? A resposta implicaria pensar a pergunta relacionalmente, revendo percursos, revisitando memórias. Talvez seja preciso pensar no que o feminismo brasileiro "envelheceu" $e$ o quanto de sua agenda carece de renovação, tendo tanto o que dizer como o que ouvir das diferentes "idades". Eis aí um bom propósito para começar a investigar a problemática de uma perspectiva "de dentro", situada e interessada.

Cremos que essas reflexões iniciais de agora para frente só poderiam ser ampliadas mediante um cuidadoso trabalho empírico, no qual aportes de sujeitos mais e menos jovens do feminismo brasileiro permitissem o cruzamento necessário para uma análise de suas narrativas. Estaríamos vendo nascer uma "quarta onda" (Matos, 2010)? No que ela se fundamenta? Que relações e alianças ela estabelece? Caso fosse assim caracterizada, seria possível retratá-la, no futuro, tal como hoje olhamos as fotos de arquivo das feministas sufragistas ou as "radicais" de final dos anos 1960 ? 
"transmissão" intergeracional no feminismo brasileiro

De nossa parte, esperamos contribuir, através da pesquisa "Estratégias de transmissão intergeracional no feminismo brasileiro", com análises que devem necessariamente ter em conta nossa experiência no movimento - a criação do Grupo Transas do Corpo ${ }^{8}$ há 24 anos - e nossos esforços também na academia.

Por fim, em todo caso, conhecer, nos limites daquilo que estamos tratando aqui, remete àquilo que está publicado e, para o mundo acadêmico, publicado em revistas especializadas. Não podemos ignorar a distância que separa jovens feministas brancas, negras, lésbicas, índias... - mesmo letradas, de suas "irmãs" adultas versadas nas linguagens das publicações oficiais. Daí a razão pela qual, em um artigo introdutório como este, nossas citações denunciam nosso próprio "adultocentrismo" de linhagem academicista.

\section{Referências bibliográficas}

AIKAU, Hokulani K., ERICKSON, Karla A. e PIERCE, Jennifer L. Feminist waves, Feminist generations. Minneapolis, University of Minnesota Press, 2007.

AlvAREZ, Sônia. A política e o político na tessitura do movimento feminista no Brasil. In: GoNÇALVES, Eliane. (org.) Desigualdades de gênero no Brasil: reflexões e experiências. Goiânia, Grupo Transas do Corpo, 2004, pp.15-32.

Alves, Branca Moreira e PITANGUI, Jaqueline. O que é feminismo. São Paulo, Brasiliense, 1981.

AwID. Financial Sustainability for Women's Movement's Worldwide. USA, 2007.

BRITO DA MOTTA, Alda. Geração, a "diferença" do feminismo. I Simpósio Internacional O Desafio da Diferença - articulando gênero, raça $e$ classe. Salvador, UFBA, abr. 2000 [http://www.desafio.ufba.br/gt7001.html - acesso em 01/09/2010].

\footnotetext{
8 Para detalhes sobre a organização: www.transasdocorpo.org.br.
} 
CELIBERTI, Lilian. Jovens feministas. Feministas jovens. In: PAPA, Fernanda de Carvalho e SoUZA, Raquel. (orgs.) Jovens feministas presentes. São Paulo, Unifem/Friedrich Ebert Stiftung/Ação Educativa, 2009, pp.150-155.

CHINCHILLA, Norma Stoltz. Ideologías del feminismo: liberal, radical y marxista. In: LEON, Magdalena. (org.) Sociedade, subordinación y feminismo: debates sobre la mujer en América Latina y el Caribe. Bogotá, Magdalena Leon/ACEP, 1982, pp.215-238.

CORRÊA, Mariza. Do feminismo aos estudos de gênero no Brasil: um exemplo pessoal. Cadernos Pagu (16), Campinas-SP, Núcleo de Estudos de Gênero - Pagu/Unicamp, 2001, pp.13-30.

DiETz, Mary G. Current controversies in feminist theory. Annual Review of Political Science (6), 2003, pp.399-431.

DuARTE, Constância Lima de. Feminismo e literatura no Brasil. Estudos Avançados 17 (49), São Paulo, 2003, pp.150-172.

EstimA, Fernanda. Como nossos pais. Teoria e Debate (86), São Paulo, Fundação Perseu Abramo, jan./fev. 2010, pp.36-41.

Fougeryrollas-SchWEBEL, Dominique. Movimientos feministas. In: HIRATA, Helena et alii. (orgs.) Diccionario critico del feminismo. Madrid, Editorial Síntesis, 2002, pp.158-163.

Franchetto, Bruna; CAVAlCANTI, Maria Laura Viveiros de Castro e HeIlborn, Maria Luiza. Antropologia e feminismo. In: Perspectivas antropológicas da mulher, vol. 1. Rio de Janeiro, Zahar, 1981, pp.1147.

GALLOP, Jane. "Women" in Spurs and nineties feminism. In: FEDER, Ellen K. et alii. (orgs.) Derrida and feminism: recasting the question of woman. New York, Routledge, 1997, pp.7-19.

GONÇALVES, Eliane. Vidas no singular: noções sobre mulheres "sós" no Brasil contemporâneo. Tese de doutorado em Ciências Sociais, IFCH/Unicamp, 2007.

. Where was I in the 80s? Notes about feminism in Brazil. Cambridge, Harvard Center for Population and Development Studies, 1999 (final course paper, unpublished). 
"transmissão" intergeracional no feminismo brasileiro

GoUVEIA, Taciana. Antinomias e contradições: a dinâmica da institucionalidade. In: ÁVILA, Maria Betânia. (org.) Textos e imagens do feminismo: mulheres construindo a igualdade. Recife, SOS Corpo, 2011, pp.239-286.

GRANT, Judith. Fundamental feminism. New York, Routledge, 1993.

HAWKESSWORTH, Mary. A semiótica de um enterro prematuro: o feminismo em uma era pós-feminista. Estudos Feministas 14 (3), Florianópolis, 2006, pp.737-764.

Hemmings, Clare. Contando estórias feministas. Estudos Feministas 17 (1), Florianópolis, 2009, pp.215-241.

HoOKS, Bell. Sisterhood: political solidarity between women. In: FRIEDMAN, Marylin e WeISS, Penny. (orgs.) Feminism and community. Philadelphia, Temple University Press, 1995, pp.293-315.

KNUDSEN, Patrícia Porchat Pereira da Silva. Conversando sobre psicanálise: entrevista com Judith Butler. Estudos Feministas 18 (1), Florianópolis, abr. 2010, pp.161-170 [http://www.scielo.br/pdf/ ref/v18n1/v18n1a09.pdf - acesso em 16/02/2011].

LUCENA, Eleonora de. Quero empoderar as mulheres de baixa renda. Folha de S.Paulo, 08/03/2011 [http://www1.folha.uol.com.br/fsp/ cotidian/ff0803201116.htm - acesso em 08/03/2011].

MACHADO, Maria das Dores Campos e LINS DE BARROS, Myriam M. Gênero, geração e classe: uma discussão sobre as mulheres das camadas médias e populares do Rio de Janeiro. Estudos Feministas 17 (2), Florianópolis, 2009, pp.369-393 [http://www.scielo.br/pdf/ ref/v17n2/05.pdf - acesso em 6/10/2010].

MACHADO, Marília Novaes da Mota. A feminista, sua mãe, seus filhos e netos. Interações VII (13), São Paulo, 2002, pp.101-111.

MACROBBIE, Angela. Pós-feminismo e cultura popular: Bridget Jones e o novo regime de gênero. Cartografias: estudos culturais $e$ comunicação, Porto Alegre, nov. 2006, s.p. (Tradução Márcia Rejane Messa) [http://www.pucrs.br/famecos/pos/cartografias/artigos/ mcrobbie_posfeminismo.pdf - acesso em 01/10/2010]. 
MADEIRA, Drica. Movimento das mulheres: moderno sem abrir mão de seus objetivos, entrevista a Walter Sorrentino [http://www.waltersorrentino.com.br/2010/03/24/movimento-dasmulheres-moderno-sem-abrir-mao-de-seus-objetivos - acesso em 23/09/2010].

MANINI, Daniela. A crítica feminista à modernidade e o projeto feminista no Brasil dos anos 70 e 80. Cadernos AEL (3/4), Campinas-SP, 1995/96, pp.45-67.

MATOS, Marlise. Movimento e teoria feminista: é possível reconstruir a teoria feminista a partir do sul global? Revista de sociologia e política 18 (36), jun. 2010, pp.67-92.

MELO, Érica Isabel. Cultura feminista Riot Girl em São Paulo. Dissertação de mestrado em Sociologia, Unicamp, 2008.

MORAES, Maria Lygia Quartim. Feminismo, movimento de mulheres e a (re)construção da democracia em três países da América Latina. Primeira Versão nº 121. Campinas, IFCH/Unicamp, 2003.

PAPA, Fernanda de Carvalho e SOUZA, Raquel. (orgs.) Jovens feministas presentes. São Paulo, Unifem/Friedrich Ebert Stiftung/Ação Educativa, 2009.

PEDRO, Joana Maria. Narrativas fundadoras do feminismo: poderes $e$ conflitos (1970-1978). Revista Brasileira de História 26 (52), São Paulo, 2006, pp.249-272.

PINTO, Céli Regina Jardim. Feminismo, história e poder. Revista Sociologia Política 18 (36), Curitiba, jun. 2010, pp.15-23.

Uma história do feminismo no Brasil. São Paulo, Fundação Perseu Abramo, 2003 (Coleção História do povo brasileiro).

PISCITELLI, Adriana. Re-criando a (categoria) mulher? Textos Didáticos (48), Campinas-SP, nov. 2002, pp.7-42.

RAGO, Margareth. Adeus ao feminismo? Feminismo e (pós) modernidade no Brasil. Cadernos AEL (3/4), Campinas-SP, 1995/96, pp.11-43.

ROSEMBERG, Fúlvia. Estudos sobre a mulher e relações de gênero. In: Miceli, Sérgio. (org.) A Fundação Ford no Brasil. São Paulo, Fapesp/Sumaré, 1993, p.207. 
"transmissão" intergeracional no feminismo brasileiro

RuPP, Leila. Sexualidade e política no começo do século XX: o caso do movimento internacional de mulheres. Labrys estudos feministas (1/2), Brasília, jul./dez. 2002 [http://vsites.unb.br/ih/his/ gefem/labrys1_2/femininos.html - acesso em 01/12/2005].

SARTI, Cynthia A. O feminismo brasileiro desde os anos 1970: revisitando uma trajetória. Revista de Estudos Feministas (12/2), Florianópolis; 2004, pp.35-50.

SIMPSON, Roona. Contemporary spinsterhood in Britain: gender, partnership status and social change. Tese de doutorado, University of London, 2005.

SOARES, Vera. Movimentos feministas: paradigmas e desafios. Revista Estudos Feministas Especial, Florianópolis, 1994, pp.11-24.

STACEY, Judith. Is academic feminism an oxymoron? Signs 25 (4), 2000 , pp.1189-1194. [http://www.jstor.org/stable/3175510 - acesso em 14/10/2010].

TERRAIL, Jean-Pierre. Transmissões intergeracionais. In: HIRATA, Helena et alii. (org.) Dicionário crítico do feminismo. São Paulo, UNESP, 2009, pp.279-283.

TOMIZAKI, Kimi. Apresentação do dossiê "De uma geração à outra: a dimensão educativa dos processos de transmissão intergeracional". Educação \& Sociedade, vol. 31, $\mathrm{n}^{\circ}$ 111, Campinas-SP, 2010, pp.321-326.

ZANETTI, Julia Paiva. Jovens feministas. Um estudo sobre a participação juvenil no feminismo. Dissertação de mestrado em Educação, Universidade Federal Fluminense, 2009. 